\title{
Buffering Supercapacitor Mechanism based on Bidirectional DC/DC Converter for Mini All-Terrain Vehicle Application
}

\author{
Syifaul Fuada" ${ }^{* 1}$, Braham Lawas Lawu², Bommegowda Kabbala Basavarajappa ${ }^{3}$ \\ ${ }^{I}$ Program Studi Sistem Telekomunikasi, Universitas Pendidikan Indonesia, Bandung, 40154, Indonesia \\ ${ }^{2}$ PT. Perusahaan Listrik Negara (PLN) UPP Kitring, Muara Taweh, Barito Utara, Kalimantan Tengah, 73811, Indonesia \\ ${ }^{3}$ Department of Electronics \& Communication Engineering, N.M.A.M. Institute of Technology, Nitte, Udupi District, Karnataka, \\ 574110, India
}

\begin{abstract}
A R T I C LE INFO
Article history:

Received: 12 June, 2020

Accepted: 09 July, 2020

Online: 28 July, 2020
\end{abstract}

Keywords:
Non-isolated Bidirectional
DC/DC Converter
Boost Mode
Supercapacitor
Mini All-terrain Vehicle (ATV)

\section{Introduction}

Battery Management System (BMS) is one of many ways or strategies to maintain battery in excellent performance and health conditions, which is widely implemented today, especially in the electrical vehicles, e.g., reported by [1]-[5]. Most of electric vehicles use DC source (rechargeable battery) as the main power. BMS contains several issues, e.g., 1) remaining run-time information; 2) battery-capacity monitoring; 3) charge control; and 4) charge-cycle counting [6]. BMS allows the battery of electric vehicles to have a longer life time, and it cannot be

\footnotetext{
"Corresponding Author: Syifaul Fuada, Program Studi Sistem Telekomunikasi, Universitas Pendidikan Indonesia, Bandung, Syifaulfuada@upi.edu www.astesj.com

https://dx.doi.org/10.25046/aj050430
}

damaged easily because the battery indicator is managed well and always monitored. For this reason, some research uses a Supercapacitor as a secondary power besides the use of the primary battery; it has very fast in charging-discharging times. The Supercapacitor has a high density so it can be utilized to prevent the primary battery from the sudden voltages or currents in a short time due to energy fluctuation. Prior works related to battery/Supercapacitor for energy storage system have been presented by [7]-[10].

This work will focus on the battery-capacity monitoring issue on the BMS. There are various BMS types; one of them is the Bidirectional DC/DC converter, which is a circuit formed by Buck 
and Boost converters. This type has been reported in [11]-[14]. In this work, Buck-Boost mode is chosen due to easy operation; we can control the voltage/current output by Pulse Width Modulation (PWM). Moreover, Buck-Boost mode has a low-cost implementation and it has a high-efficiency. Based on the switching technique, DC/DC converter is divided into two parts, i.e., non-isolated and isolated topologies [15]. Non-isolated serves many advantages compared to isolated-topology one, such as simple circuit structure, and it contains little electronic components. Hence, the circuit dimension/size can be reduced. Furthermore, the copper losses in the Transformators component and heat waste caused by the power MOSFET' switching can be minimized.

In this work, a non-isolated topology is selected. The illustration of the converter power flow is illustrated in Figure 1(a) while Figure 1(b) shows the basic non-isolated topology. As we can see, the Bidirectional DC/DC converter have two ways (directions) of the current flow. If the $\mathrm{V}_{\mathrm{A}}$ node is the input voltage (Buck mode), then the " $\mathrm{V}_{\mathrm{B}}$ " node acts as the output voltage, whereas if the " $\mathrm{V}_{\mathrm{B}}$ " node is input voltage (Boost mode), then the " $\mathrm{V}_{\mathrm{A}}$ " node acts as the input voltage.

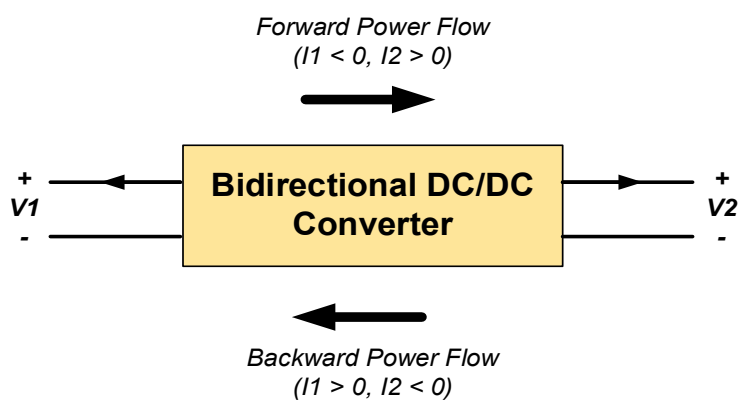

(a)

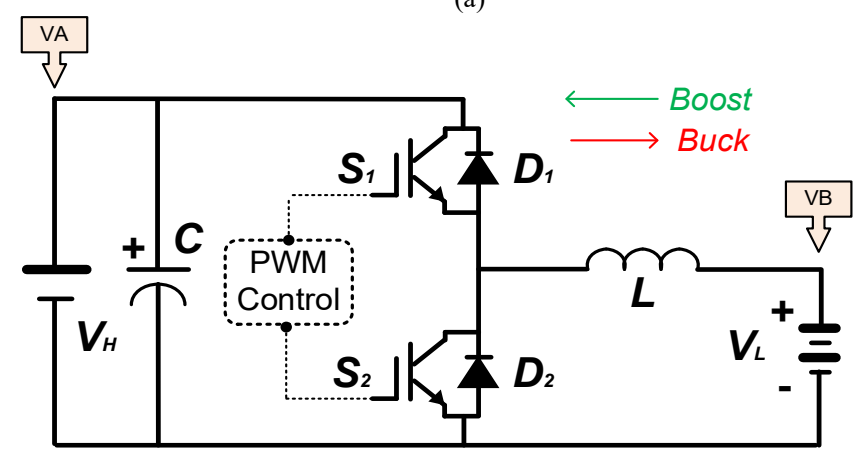

(b)

Figure 1: (a) Power flow illustration of the Bidirectional DC/DC converter, reproduced from [16] (b) Basic topology of Bidirectional DC/DC converter to charge and discharge exchange on Supercapacitor, reproduced from [16]

According to Figure 1(a), the basic circuit has 4 modes, which is [16]:

- Mode I: The DC/DC converter acts in buck mode when the high voltage $\left(\mathrm{V}_{\mathrm{H}}\right)$ is greater than the reference value $\mathrm{V}_{\text {ref. }}$ In this mode, the $\mathrm{DC} / \mathrm{DC}$ converter controls the current to charge the Supercapacitor.

- Mode II: The DC/DC converter acts in boost mode when $\mathrm{V}_{\mathrm{H}}$ falls below the reference value. In this mode, the Supercapacitor discharges.
- $\quad$ Mode III: When Supercapacitor is fully charged, the DC/DC converter shuts down to avoid damaging the Supercapacitor.

- Mode IV: When the Supercapacitor is fully discharged, the conditioner shutdown until the supply produces sufficient current to resume charging of the Supercapacitor.

Mode I and Mode III are used to configure the Bidirectional $\mathrm{DC} / \mathrm{DC}$ converter in a Buck mode (charging mechanism). This mode has been used in previous work to decrease the voltage of the external Boost converter module from $36 \mathrm{~V}_{\mathrm{DC}}$ to $18 \mathrm{~V}_{\mathrm{DC}}$ and charge the Supercapacitor [17]. Whereas to discharge and buffer the voltage and current for an electrical All-Terrain Vehicle (ATV) motor, we will use Mode II and Mode IV. The difference between our work to [7-10] is the use of Microcontroller as the primary control. The STM32F4 Microcontroller was used due to serve a user interface feature, i.e., STMStudio. Therefore, we do not need to design a graphical user interface (GUI) from scratch to display the charge-discharge Supercapacitor mechanism. We just employ this software to save effort in designing and implementing the Bidirectional DC/DC converter. As stated by T. Adiono, et al., [18] and A.T. Agung, et al., [19] that an open-source software enables us to cut the required time during the design and implement a specified system.

The discussion of this paper is divided into four sections, which are: (1) Introduction which presents the research background and purpose; (2) Material and Methods which discusses the Bidirectional DC/DC converter design and its simulation employing LTspice ${ }^{\circledR}$ software; (3) Results and Analysis which shows the experimental data of Supercapacitor discharging mechanism in the real test; the last one is (4) Conclusion and References.

\section{Materials and Methods}

\subsection{Boost Converter: Overview}

The boost converter is one of the DC/DC Converter types functioned to increase certain voltage levels. Commonly, the Boost converter circuit has a topology, as illustrated in Figure 2 (a) and the working principle, as in Figure 2 (b). Based on Figure 2(a), we can see that Boost converter circuit contains several electronics components: a switch represented by $S$, a Diode represented by $D$, an Inductor represented by $L$, a Capacitor represented by $C$, a load represented by $R$, and $V S$ as a source voltage or input voltage.

Similar to the Buck converter circuit, the Boost converter circuit also has two modes: Continuous Conduction Mode (CCM) and Discontinuous Conduction Mode (DCM) with respect to the current flowing at the Inductor $\left(i_{L}\right)$

The difference between these modes lies in the value of the components inside and also the current passing through the Inductor. In CCM mode, the current flow through the inductor will never be zero. While in DCM mode, the current flow through the inductor will have a value when the current flow is zero. The relationship between the output and input voltage in the boost converter can be written as an Eq. (1),

$$
V_{\text {Out }}=\frac{V_{S}}{1-D}
$$




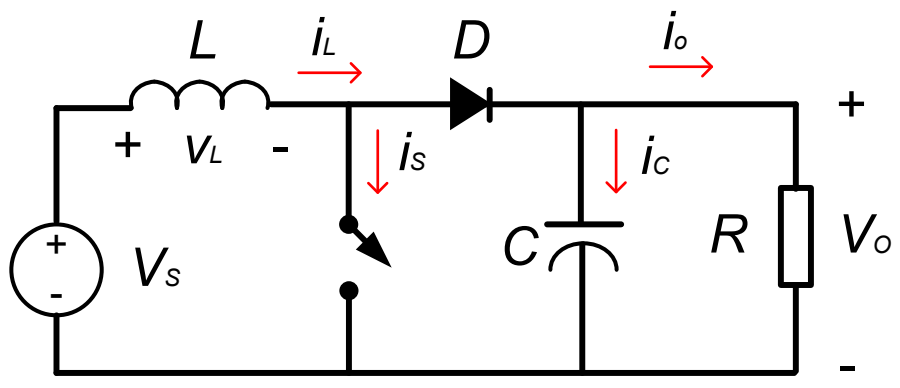

(a)

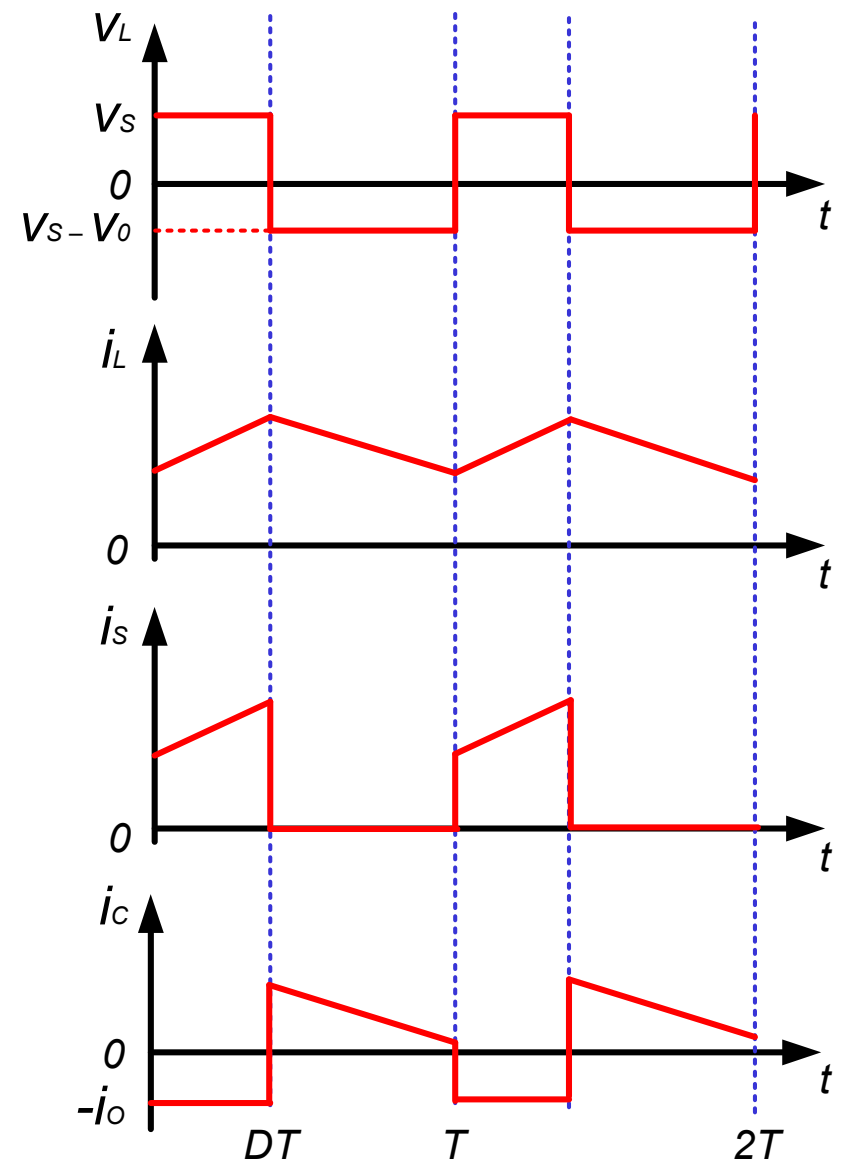

(b)

Figure 2: (a) Boost converter circuit configuration and (b) Boost converter waveform, obtained from [1]

Where $V_{O}$ is output voltage, $V_{S}$ is source voltage (input voltage), and $D$ is the used Duty cycle in the Bidirectional DC/DC converter. In a Boost converter mode, the CCM and DCM limits are expressed by Eq (2),

$$
L_{b}=\frac{(1-D)^{2} D R}{2 f}
$$

Where $f$ can be defined as $\mathrm{F}_{\mathrm{SW}}$ and $R$ is a dummy load. If $L>L_{b}$, then Boost converter will be on CCM mode. The use of capacitor as filters in this mode must be set to have a minimum value. Accordingly, it does not have a large DC ripple voltage $\left(V_{r}\right)$. To limit it, the Capacitor value used for Boost mode must be greater than Eq. (3),

$$
C_{\min }=\frac{D V_{O}}{V_{r} R f}
$$

From Eq. (2) and Eq. (3) the Inductor and Capacitor values can be found, which is then applied in the circuit. Besides, we can also determine the operated frequency value in the circuit.

\subsection{Bidirectional DC/DC Converter in Boost Mode: Design}

We have a Supercapacitor designed by ourselves as the secondary power of the mini ATV motor rated in $25 \mathrm{~V}_{\mathrm{DC}} 8 \mathrm{~F}$. This Supercapacitor contains several commercially available Electrolytic Capacitor/Condensator (Elco) connected in series/parallel. We charged the Supercapacitor at least under 22 $\mathrm{V}_{\mathrm{DC}}$ to keep it healthy, precisely is $18 \mathrm{~V}_{\mathrm{DC}}$. To buffer the DC motor of mini ATV, we need to increase the minimum voltage of Supercapacitor, that is $18 \mathrm{~V}_{\mathrm{DC}}$ to $\mathrm{DC}$ motor working voltage, that is $36 \mathrm{~V}_{\mathrm{DC}}$.

Figure 3 shows the complete circuit of the Bidirectional DC/DC converter that has dual-mode in a single circuit: Boost and Buck.

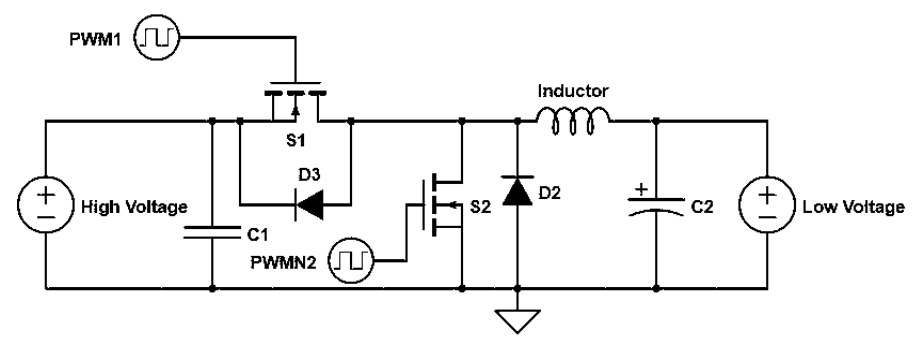

Figure 3: Basic structure of the Bidirectional DC/DC converter with Buck and Boost built-in

Afterward, we identify the desired system so that we can calculate the value of the electronic components needed in the circuit. The following are system specifications based on the specified identification.

- The bidirectional DC/DC converter consists of two P75NF75 power MOSFETs as the switching part, STM32F4 Discovery as the microcontroller unit, ACS712 as the current sensor, inductor with PQ type, and TLP250 as the gate driver.

- Input voltage $\left(V_{\text {in }}\right)=18 \mathrm{~V}_{\mathrm{DC}}$

- $\quad$ Desired output voltage $\left(V_{\text {out }}\right)=36 \mathrm{~V}_{\mathrm{DC}}$

- Desired discharging current in the Supercapacitor $\left(I_{o u t}\right)$ is about $4 \mathrm{~A}$

- $\quad$ Switching frequency $\left(F_{S W}\right)$ used is $10 \mathrm{kHz}$ based on the gate driver specification (IC TLP250)

As a reference calculation, we use the formula from [20]. From the above parameters, the Duty cycle value can be found by Eq. (1), which $V S$ is noted as Vin

$$
D=1-\frac{V_{\text {in }}}{V_{\text {out }}}=1-\frac{18}{36}=0.5
$$

where the determination of the minimum inductor value is referred to Eq. (2), so $L_{b}$ would be

$$
L_{b}=\frac{(1-D)^{2} D * R}{2 f}=56.25 u H
$$

While to determine the minimum value of Capacitor, Eq. (3) was used. Furthermore, $C_{\min }$ would be 


$$
C_{\min }=\frac{D V_{O}}{V_{r} R f}=555.55 \mathrm{uF}
$$

Later, we calculate the values of inductor and capacitor needed for the circuit. The formula for the inductor is given by Eq. (4),

$$
V_{L}=L \frac{d i}{d t}
$$

Where $L$ is the value of the inductor, $V_{L}$ is the voltage at the inductor, $d t$ is the switching period, $d i$ is the ripple current. $D$ is the selected Duty cycle. According to the specification, our experiment used $\mathrm{F}_{\mathrm{sw}}=10 \mathrm{kHz}$ and $50 \%$ of Duty cycle, then, the calculation for the inductor would be,

$$
\begin{aligned}
36-18 & =L \frac{1.2}{0.5 * 10 \mathrm{kHz}} \\
L & =750 \mathrm{uH}
\end{aligned}
$$

To seek the Capacitor value, we used Eq. (5),

$$
i_{c}=C \frac{d v}{d t}
$$

where $\mathrm{C}$ is the used Capacitor value, $i_{\mathrm{c}}$ is the Capacitor current. By setting $F_{S w}=10 \mathrm{kHz}$ and $\mathrm{D}=50 \%$, then the calculation for the capacitor would be,

$$
C=\frac{1.2 \mathrm{~A} * 0.5 * 10 \mathrm{kHz}}{0.18 \mathrm{~V}}=333.33 \mathrm{uF}
$$

But in practical design, we used $2.5 \mathrm{mH}$ and $100 \mu \mathrm{F}$ of inductor and capacitor values, respectively.

We used TLP250 for gate driver on the Power MOSFET that has a maximum operating frequency at $25 \mathrm{kHz}$. As stated in the system requirement, we only used $10 \mathrm{kHz}$ as the PWM switching frequency. The gate driver configuration is depicted as Figure 4,

The PWM output from the microcontroller will trigger the Gate of the MOSFETS. Our Bidirectional DC/DC converter circuit is needed a complementary PWM to work. To do this case, we configure the microcontroller in complementary PWM in which the STM32F4 microcontroller has a feature for it.

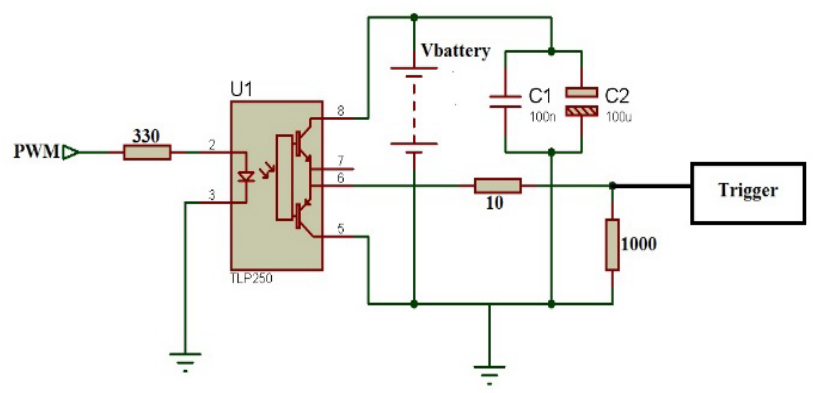

Figure 4: The Gate driver schematic of Bidirectional DC/DC converter in Boost mode

The Dead time also can be involved to prevent both of the two MOSFETs shorted at the same time. The dead time calculation can be written as expressed by [17]

$$
\begin{aligned}
& t_{\text {dead }}=\mid\left(t_{D_{\_} O F F_{-} M A X}-t_{D_{-} O N_{-} M I N}\right)+\left(t_{P D D_{-} M A X}-\right. \\
& \left.t_{P D D_{-} M I N}\right) \mid * 1.2
\end{aligned}
$$

\subsection{Bidirectional DC/DC Converter in Boost Mode: Simulation}

We used LTSpice ${ }^{\circledR}$ software to simulate the Bidirectional DC/DC converter in boost mode as shown in Figure 5. The circuit in a simulation has two outputs, which are voltage and current outputs. We generated the PWM signal as an input signal to the MOSFET's gate by setting the voltage source as the PWM. In line with the system identification, Diode MUR1560 and MOSFET type P75NF75 were chosen. To obtain valid results in ideal conditions, the components model and its parameters inserted in LTSpice ${ }^{\circledR}$ that are precisely the same as the MUR1560 and P75NF75 datasheets. Other parameters set for the simulation is shown in Table 1

Table 1. Simulation Parameters

\begin{tabular}{|c|c|c|}
\hline No & Parameters & Value \\
\hline 1 & $\mathrm{~V}_{\text {in }}$ & $18 \mathrm{~V}_{\mathrm{DC}}$ \\
\hline 2 & $\mathrm{C}_{\text {in }}$ & $100 \mu \mathrm{F}$ \\
\hline 3 & $\mathrm{C}_{\text {out }}$ & $100 \mu \mathrm{F}$ \\
\hline 4 & $\mathrm{R}_{\text {out }}$ & $10 \Omega$ \\
\hline 5 & $L$ & $2.5 \mathrm{mH}$ \\
\hline 6 & $F_{\text {sw }}$ & $10 \mathrm{kHz}$ \\
\hline 7 & Duty cycle & $50 \%(0.5)$ \\
\hline 8 & Supercapacitor & $8 \mathrm{~F}$ \\
\hline
\end{tabular}

After the circuit has been constructed in LTSpice $\AA$, we convert it into a block as visualized in Figure 5, where $\mathrm{X} 1$ is our Bidirectional DC/DC converter, V1 is voltage input with $18 \mathrm{~V}_{\mathrm{DC}}$, and $R_{1}$ is a dummy load with $10 \Omega$. Based on the real measurement using digital Multimeter, the DC motor of the mini ATV has total resistance about $10 \Omega$. Therefore, we set it as a load to represent DC motor in our simulation. The simulation result is shown in Figure 6, we can see that the output voltage is $35.026818 \mathrm{~V}_{\mathrm{DC}}$ when the Duty cycle is set $50 \%$. The average of output current flows in the circuit is $3.2329 \mathrm{~A}$ and $3.3171 \mathrm{~A}$ of RMS current. The output voltage will swing in the initial state from $0 \mathrm{~V}$ to the maximum of $40 \mathrm{~V}_{\mathrm{DC}}$ until it reached the steady state of $\sim 36 \mathrm{~V}_{\mathrm{DC}}$, that is $35.026818 \mathrm{~V}_{\mathrm{DC}}$ while the output current will swing in the initial state from $0 \mathrm{~A}$ to the maximum of $4 \mathrm{~A}$. In this Boost mode, the output voltage will buffer mini ATV. For data comparison, the Duty cycles in LTSpice ${ }^{\circledR}$ simulation are varied from $50 \%$ to $30 \%$, $40 \%$ and $60 \%$ and we obtained $23.367980 \mathrm{~V}_{\mathrm{DC}}, 27.424739 \mathrm{~V}_{\mathrm{DC}}$, and $38.787089 \mathrm{~V}_{\mathrm{DC}}$, respectively.

\section{Results and Analysis}

After the simulation has been done perfectly, we tested the Supercapacitor performance whether it can increase the voltage from 18 to $36 V_{D C}$ or not. As specified in system identification, the output voltage should stay at approximately $36 \mathrm{~V}_{\mathrm{DC}}$ even the input voltage from the Supercapacitor is decreasing. To meet the qualification, we set the experiment parameters as Table 2 . 


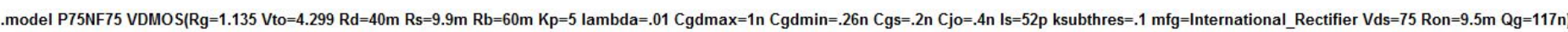
.model MUR1560 D(ls=14.956E-9 N=1.8393 Rs=18.550E-3 lkf=.19576 Cjo=270.00E-12 M=.47268 Vj=.51459 lsr=534.12E $-12 \mathrm{Nr}=3 \mathrm{Bv}=600 \mathrm{tt}=61 \mathrm{n} \mathrm{Tikf=0.01} \mathrm{lave=15} \mathrm{Vpk=350} \mathrm{mfg=Rohm} \mathrm{type=FastRecovery)}$

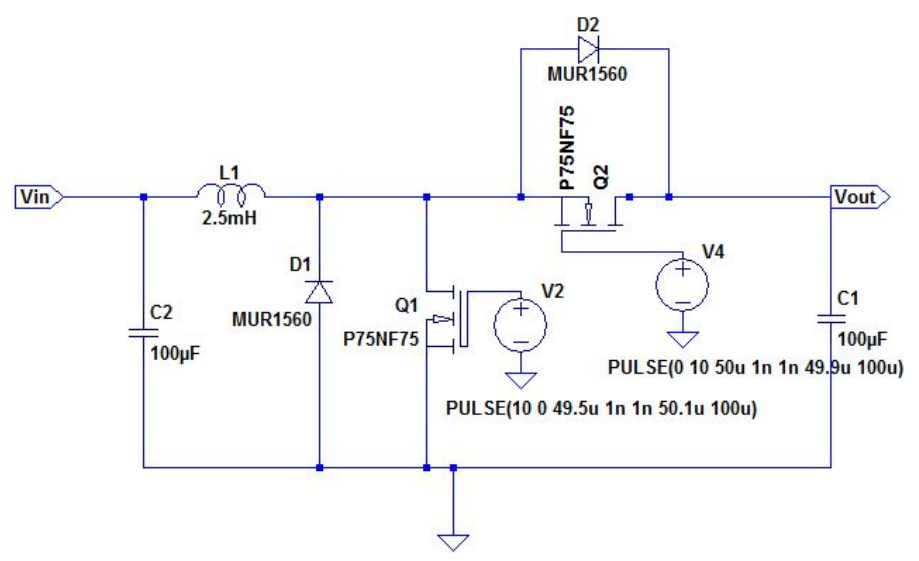

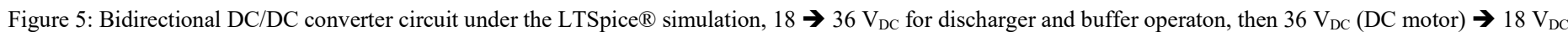
(Supercapacitor) for charger operation. This simulation will focus on discharger/buffer operation from $18 \mathrm{~V}_{\mathrm{DC}}$ (Supercapacitor) to $36 \mathrm{~V}_{\mathrm{DC}}$ (DC motor)

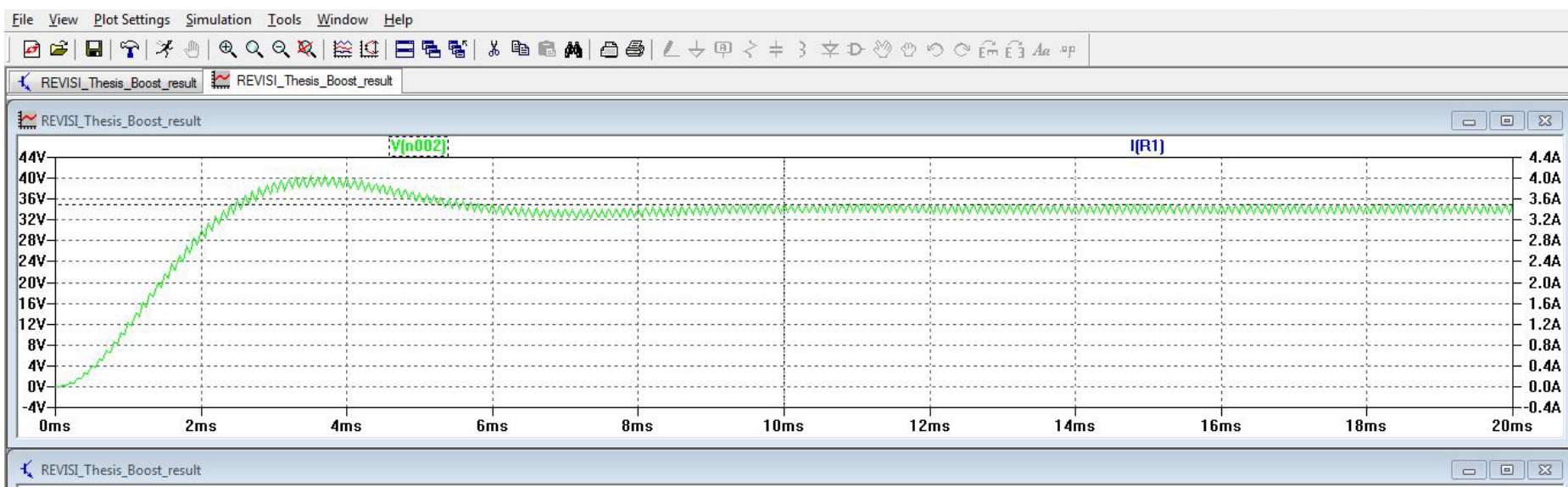

1. REVISI_Thesis_Boost_result
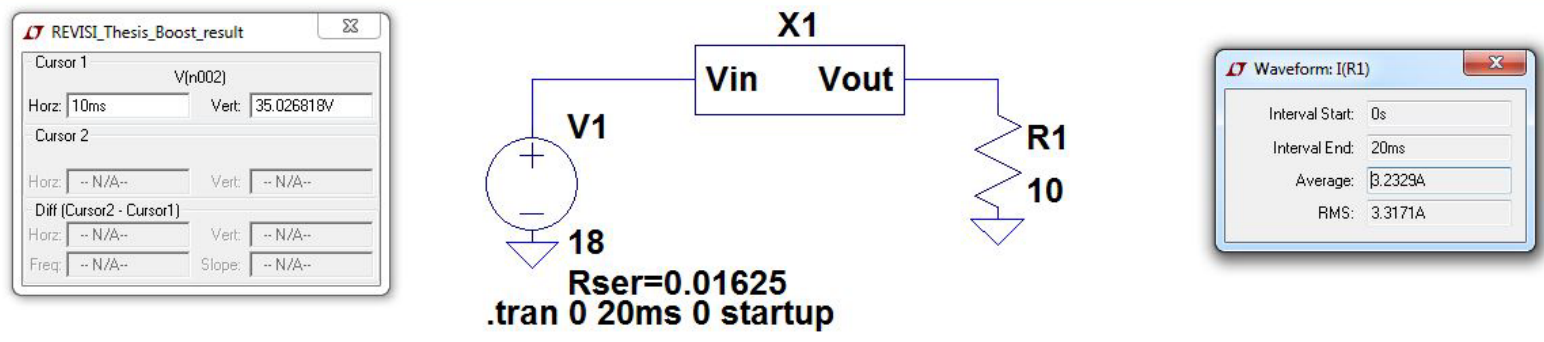

.tran $020 \mathrm{~ms} 0$ startup

Left-Click to redraw I(R1)[A], Right-Click to edit expression. Control-Left Click to integrate

Figure 6: Simulation result of the Bidirectional DC/DC converter on Boost mode with Duty cycle $=50 \%$

A Photograph of experimental setting to verify the circuit design and the printed-circuit board (PCB) of the designed bidirectional DC/DC converter are visualized in Figure 7(a) and Figure 7(b), respectively.

We set the voltage limit at the Supercapacitor to be $10 \mathrm{~V}_{\mathrm{DC}}$ minimum and $18 \mathrm{~V}_{\mathrm{DC}}$ maximum (fully-charged). Thus, when the $\mathrm{DC} / \mathrm{DC}$ converter in a boost mode, it will be no longer in this mode if the Supercapacitor voltage reaches $10 \mathrm{~V}_{\mathrm{DC}}$ from $18 \mathrm{~V}_{\mathrm{DC}}$.

The test scenario is the same as previous work [17]. It is shown in Figure 8 (reproduced from [17] with permission). An external Boost converter module was used to increase a $22.2 \mathrm{~V}_{\mathrm{DC}} / 5000$ mAh LiPo battery (series configuration of two 11,1 $\mathrm{V}_{\mathrm{DC}} \mathrm{LiPo}$ batteries). Afterward, this voltage output is connected to the mini ATV that requires $36 \mathrm{~V}_{\text {DC }}$ of voltage to work.

Table 2. Experiment Parameters

\begin{tabular}{|c|c|c|}
\hline No & Parameters & Value \\
\hline 1 & $V_{\text {in }}$ & $\begin{array}{c}18 \mathrm{~V}_{\mathrm{DC}} \text { (Supercapacitor voltage when it is } \\
\text { fully charged) }\end{array}$ \\
\hline 2 & $L$ & $2.5 \mathrm{mH}$ \\
\hline 3 & $F_{S w}$ & $10 \mathrm{kHz}$ \\
\hline 4 & Supply at the Gate driver & single supply $\left(11,1 \mathrm{~V}_{\mathrm{DC}}\right)$ \\
\hline
\end{tabular}




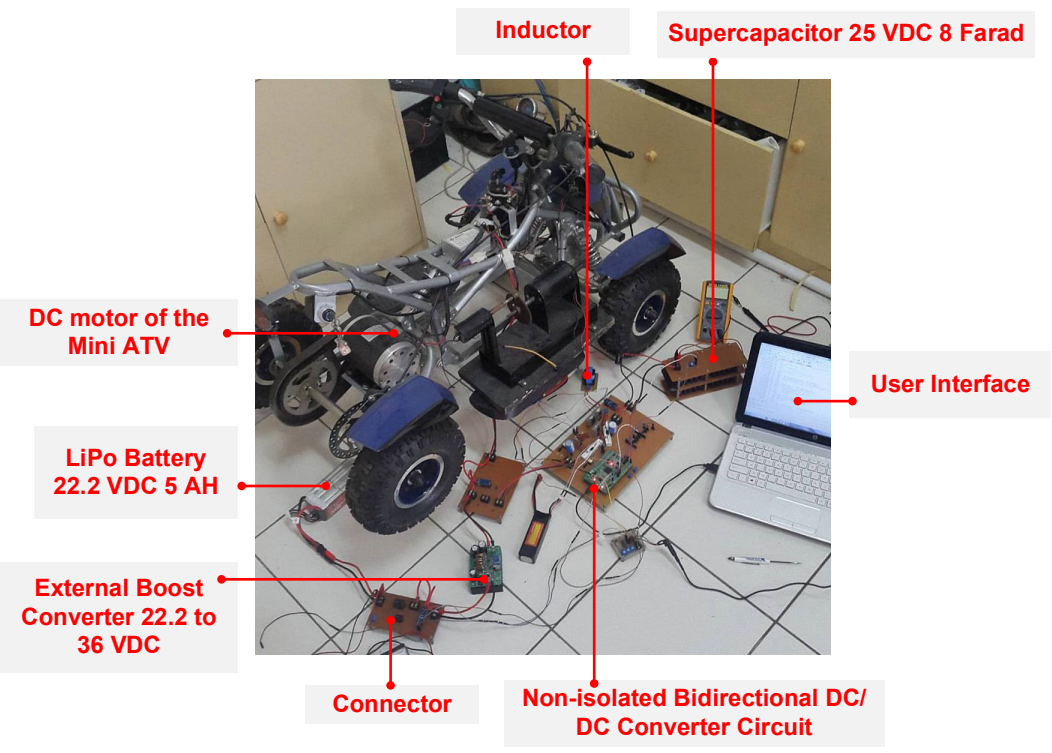

(a)

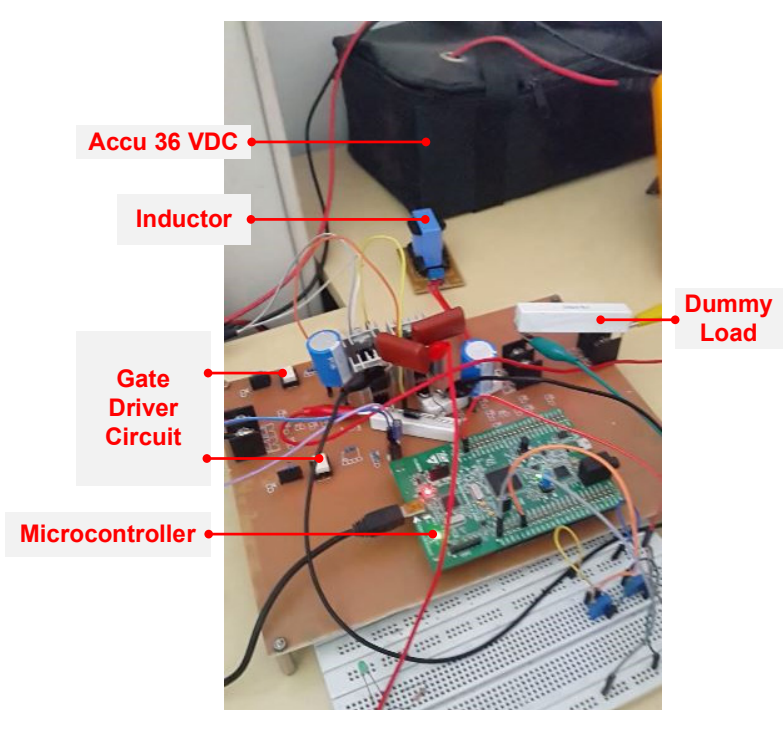

(b)

Figure 7: (a) Experimental setup containing mini ATV motor, Battery, Supercapacitor $25 \mathrm{~V}_{\mathrm{DC}} / 8 \mathrm{~F}$, electronic circuit experiments, and Laptop as user interface; (b) fabricated the Bidirectional DC/DC converter circuit in single-sided PCB

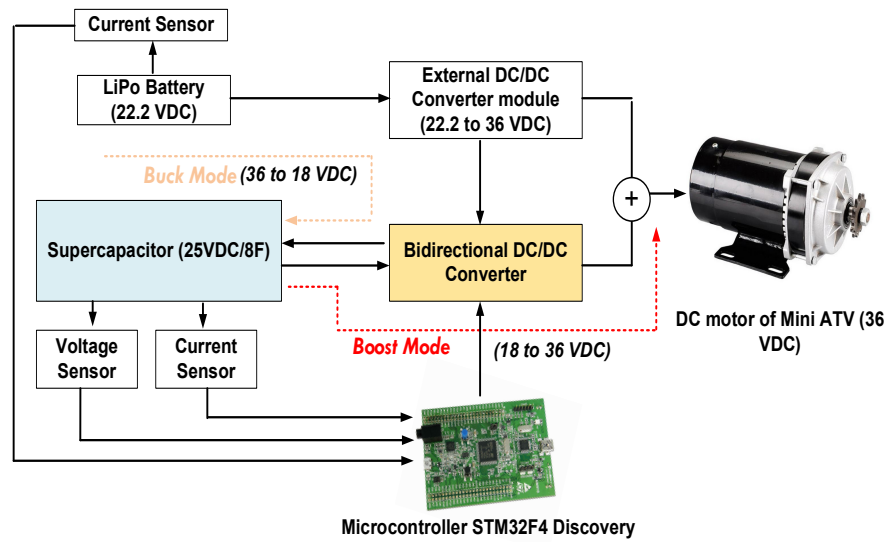

Figure 8: A Scenario for testing the performance of Bidirectional DC/DC converter in Boost mode

To monitor the Supercapacitor condition, we need a user interface. We employed the STMStudio to display the discharging voltage of the Supercapacitor. The experimental results are shown in Figure 9. The vertical axis represents Supercapacitor voltage while the horizontal axis represents Supercapacitor's discharging time. The pink line represents the Supercapacitor voltage while the orange line represents the output voltage of the Bidirectional DC/DC Converter in a boost mode. To easily understand the mentioned lines when this paper is printed in a grayscale format, we marked it as in Figure 9.

From the window, it can be seen that the output voltage stays at a certain level even the voltage at the Supercapacitor is decreasing from $17.5 \mathrm{~V}_{\mathrm{DC}}$ down to $10 \mathrm{~V}_{\mathrm{DC}}$ as pointed out by the GUI. However, the displayed values on the STMStudio is not accurate enough. Therefore, it can be used only to ensure that the output voltage is almost stable (information based on the visual observation). Digital multimeter was used to measure a real value; we got a stable voltage, i.e., $\sim 36 \mathrm{~V}_{\mathrm{DC}}$ when $50 \%$ of the Duty Cycle is set. This voltage level can be reached by controlling the PWM (Duty cycle) properly.

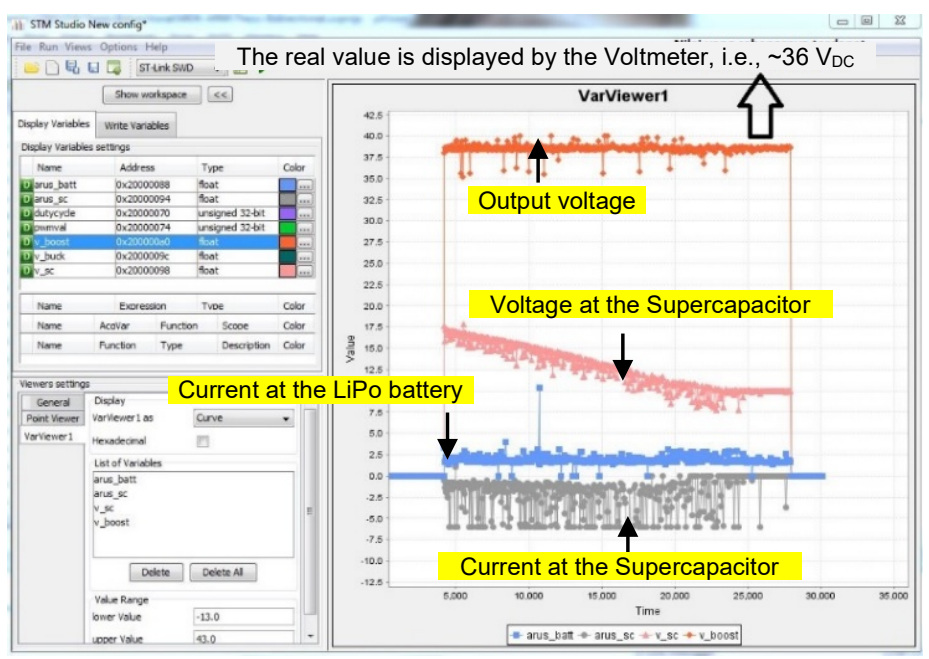

Figure 9: Plot of the Supercapacitor's voltage charging using STMStudio in Boost mode

Whereas to measure the Supercapacitors current accurately, we used the ACS712 current sensor reading in an Analog to Digital Converter (ADC). As a result, the current can be buffered to the mini ATV by the Supercapacitor varied from 0 to $6 \mathrm{~A}$. In this experiment, our circuit can work well as expected: the input of the converter can be output, and vice versa, the output can be the input.

Afterward, the simulation results as presented in Section 2.3 are compared with the laboratory measurements. We adjust PWM variations according to the simulation settings, which are $30 \%$, $40 \%$, and $60 \%$, and we obtained $25.1 \mathrm{~V}_{\mathrm{DC}}, 29.2 \mathrm{~V}_{\mathrm{DC}}$, and $36.5 \mathrm{~V}_{\mathrm{DC}}$, respectively. Table 3 is a comparison between simulation and real experiment of the Bidirectional DC/DC converter in a Boost mode. 
To make it easier to see the difference level, a graph is served as shown in Figure 10, it can be seen that there is a difference between using simulations and implementing hardware. This can occur due to several factors like tolerance factor of the used components that make it non-ideal.

Table 3: Comparison between voltage output from a simulation and implementation (real condition) on the Bidirectional DC/DC converter circuit with Boost mode

\begin{tabular}{|c|c|c|c|}
\hline No & Duty Cycle & $\begin{array}{c}\text { Output voltage in } \\
\text { Simulation }\end{array}$ & $\begin{array}{c}\text { Output voltage in } \\
\text { Implementation }\end{array}$ \\
\hline 1 & $30 \%$ & $23.367980 \mathrm{~V}_{\mathrm{DC}}$ & $25.1 \mathrm{~V}_{\mathrm{DC}}$ \\
\hline 2 & $40 \%$ & $27.424739 \mathrm{~V}_{\mathrm{DC}}$ & $29.2 \mathrm{~V}_{\mathrm{DC}}$ \\
\hline 3 & $50 \%$ & $35.026818 \mathrm{~V}_{\mathrm{DC}}$ & $32.7 \mathrm{~V}_{\mathrm{DC}}$ \\
\hline 4 & $60 \%$ & $38.787089 \mathrm{~V}_{\mathrm{DC}}$ & $36.5 \mathrm{~V}_{\mathrm{DC}}$ \\
\hline
\end{tabular}

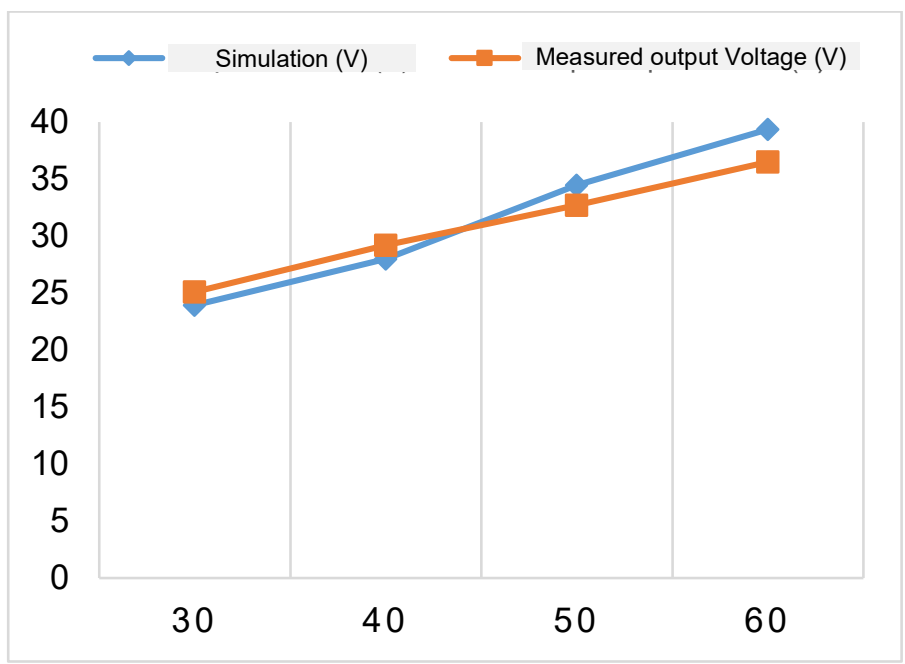

Figure 10: A Graph of simulation vs. measured output on the Bidirectional DC/DC converter circuit with Boost mode. Horizontal axis: Duty Cycle (\%) and Vertical axis: Output voltage (V)

\section{Conclusion}

Supercapacitor plays an essential role in the BMS of modern electric vehicles. By using Supercapacitor as a supplementary battery, the need for high current from the main battery can be buffered and maintained at the considered level. Thus, the main battery will have a long-time span. In this work, non-isolated bidirectional converter is chosen due to the use of fewer components than the isolated bidirectional converter. So, in terms of PCB size, it will be relatively smaller than the isolated Bidirectional DC/DC converter. The effect of the transformer's usage on isolated topology makes power losses due to overheating production. While for non-isolated, careful calculation needs to be done in determining the inductor as well as capacitor values. Thus, the circuit can operate properly, both for Boost or Buck modes. The use of the inductor on the non-isolated topology can reduce power losses.

In this work, we realize a BMS using a non-isolated bidirectional DC/DC converter controlled by the PWM. Our circuit is used as a current and voltage control system that operates in Buck and Boost. By changing the PWM Duty cycle in the Microcontroller
STM32F4, we can manually adjust the output voltage of the bidirectional DC/DC converter.

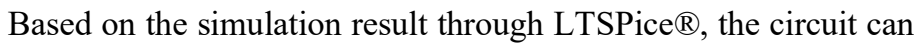
work well as expected; the output voltage is $\sim 36 \mathrm{~V}_{\mathrm{DC}}$ with $50 \%$ of Duty cycle. This voltage will be used to buffer/discharge the DC motor of mini ATV. According to the functional test, it can be seen that the supercapacitor can perform a discharging function. Hence, it can be used as a secondary power distributor to buffer voltage and current, which is then successfully implemented on the mini ATV. Discharging time of the Supercapacitor takes approximately $30-50$ seconds, depending on the battery capacity with a current of up to $6 \mathrm{~A}$. This high current can be pulled from a $25 \mathrm{VDC} / 8 \mathrm{~F}$ Supercapacitor to the mini ATV. The detail of this paper including the improved Buck mode using Resistor-Capacitor-Diode (RCD) Snubber circuit and Hybrid mode (Buck \& Boost).

In future work, we will more emphasized the effects of different construction features upon the systems functioning.

\section{Conflict of Interest}

The authors declare no conflict of interest.

\section{Acknowledgment}

We would like to thanks to Dr. Arif Sasongko and Dr. Farkhad Ihsan Hariadi from School of Electrical Engineering and Informatics Insitut Teknologi Bandung (ITB), Indonesia, for their supervision.

\section{References}

[1] I. Carlucho, R. de la Vega, M. Spina, and G. G. Acosta, 'A Modular Battery Management System for Electric Vehicles', in 2018 IEEE Biennial Congress of Argentina (ARGENCON), San Miguel de Tucumán, Argentina, 1-6, 2018. doi: 10.1109/ARGENCON.2018.8646227

[2] A. P. Talie, W. A. Pribyl, and G. Hofer, 'Electric Vehicle Battery Management System Using Power Line Communication Technique', in 2018 14th Conference on Ph.D. Research in Microelectronics and Electronics (PRIME), Prague, 225-228, 2018. doi: 10.1109/PRIME.2018.8430304.

[3] L. K. Amifia, S. A. Widayat, A. I. Cahyadi, and O. Wahyunggoro, 'Fault detection design and simulation based on battery modelling', presented at the PROCEEDINGS OF THE 12TH INTERNATIONAL CONFERENCE ON SYNCHROTRON RADIATION INSTRUMENTATION - SRI2015, New York, NY USA, p. 090008, 2016. doi: 10.1063/1.4958526

[4] D. A. Martinez, J. D. Poveda, and D. Montenegro, 'Li-Ion battery management system based in fuzzy logic for improving electric vehicle autonomy', in 2017 IEEE Workshop on Power Electronics and Power Quality Applications (PEPQA), Bogota, Colombia, 1-6, 2017. doi: 10.1109/PEPQA.2017.7981677

[5] R. Xiong, Y. Zhang, J. Wang, H. He, S. Peng, and M. Pecht, 'Lithium-Ion Battery Health Prognosis Based on a Real Battery Management System Used in Electric Vehicles', IEEE Trans. Veh. Technol., 68(5), 4110-4121, May 2019. doi: 10.1109/TVT.2018.2864688

[6] L. Buccolini, A. Ricci, C. Scavongelli, G. DeMaso-Gentile, S. Orcioni, and M. Conti, 'Battery Management System (BMS) simulation environment for electric vehicles', in 2016 IEEE 16th International Conference on Environment and Electrical Engineering (EEEIC), Florence, Italy, 1-6, 2016. doi: 10.1109/EEEIC.2016.7555475

[7] L. Kouchachvili, W. Yaïci, and E. Entchev, 'Hybrid battery/supercapacitor energy storage system for the electric vehicles', J. Power Sources, 374, 237 248, 2018. doi: 10.1016/j.jpowsour.2017.11.040

[8] A. Tahri et al., 'Management of fuel cell power and supercapacitor state-ofcharge for electric vehicles', Electr. Power Syst. Res., 160, 89-98, Jul. 2018, doi: 10.1016/j.epsr.2018.02.003.

[9] B.-H. Nguyen, R. German, J. P. F. Trovao, and A. Bouscayrol, 'Real-Time Energy Management of Battery/Supercapacitor Electric Vehicles Based on 
an Adaptation of Pontryagin's Minimum Principle', IEEE Trans. Veh. Technol., 68(1), 203-212, Jan. 2019, doi: 10.1109/TVT.2018.2881057.

[10] Z. Song, J. Hou, H. Hofmann, J. Li, and M. Ouyang, 'Sliding-mode and Lyapunov function-based control for battery/supercapacitor hybrid energy storage system used in electric vehicles', Energy, 122, 601-612, 2017. doi: 10.1016/j.energy.2017.01.098

[11] R. H. Ashique and Z. Salam, 'A High-Gain, High-Efficiency Nonisolated Bidirectional DC-DC Converter With Sustained ZVS Operation', IEEE Trans. Ind. Electron., 65(10), 7829-7840, 2018. doi: 10.1109/TIE.2018.2802457.

[12] H. Bahrami, S. Farhangi, H. Iman-Eini, and E. Adib, 'A New Interleaved Coupled-Inductor Nonisolated Soft-Switching Bidirectional DC-DC Converter With High Voltage Gain Ratio', IEEE Trans. Ind. Electron., 65(7), 5529-5538, 2018. doi: 10.1109/TIE.2017.2782221

[13] Y. Zhang, X.-F. Cheng, C. Yin, and S. Cheng, 'A Soft-Switching Bidirectional DC-DC Converter for the Battery Super-Capacitor Hybrid Energy Storage System', IEEE Trans. Ind. Electron., 65(10), 7856-7865, 2018. doi: 10.1109/TIE.2018.2798608

[14] M. Veerachary and O. K. Singh, 'Bidirectional non-isolated dc-dc converter for low-voltage DC-grid', in 2016 IEEE International Conference on Power Electronics, Drives and Energy Systems (PEDES), Trivandrum, India, 1-6, 2016. doi: 10.1109/PEDES.2016.7914408.

[15] H. Ardi, A. Ajami, F. Kardan, and S. Nikpour, 'Analysis and Implementation of a Non-Isolated Bidirectional DC-DC Converter with High Voltage Gain', IEEE Trans. Ind. Electron., 1(1), 2016. doi: 10.1109/TIE.2016.2552139.

[16] J. Zhang, 'Bidirectional DC-DC Power Converter Design Optimization, Modeling and Control', Diss. Va. Polytech. Inst. State Univ., 3-5, 2008.

[17] B. L. Lawu, S. Fuada, S. Ramadhan, A. F. Sabana, and A. Sasongko, 'Charging supercapacitor mechanism based-on bidirectional DC-DC converter for electric ATV motor application', in 2017 International Symposium on Electronics and Smart Devices (ISESD), Yogyakarta, 129132, 2017. doi: 10.1109/ISESD.2017.8253318.

[18] T. Adiono, S. F. Anindya, S. Fuada, K. Afifah, and I. G. Purwanda, 'Efficient Android Software Development Using MIT App Inventor 2 for BluetoothBased Smart Home', Wirel. Pers. Commun., 105(1), 233-256, 2019. doi: 10.1007/s11277-018-6110-x.

[19] A. T. Agung, S. Fuada, and T. Adiono, 'IMPLEMENTASI ASSET MANAGEMENT DENGAN SNIPE-IT DI PUSAT MIKROELEKTRONIKA INSTITUT TEKNOLOGI BANDUNG', Simetris J. Tek. Mesin Elektro Dan Ilmu Komput., 10(1), 243-258, 2019. doi: 10.24176/simet.v10i1.2961.

[20] M. H. Rashid, Ed., Power Electronics Handbook. Amsterdam, The Netherlands: Elsevier, 2007. 